\title{
Sturge-Weber Syndrome- A Rare Case Report
}

\author{
DivyankPathak ${ }^{1}$,Dhananjay.Y.Shrikhande ${ }^{2}$, NileshManiya ${ }^{3}$, \\ Somdeepak Reddy ${ }^{4}$, Rushik R Bhuva ${ }^{5}$ \\ ${ }^{1}$ Post graduate student, Department of Pediatrics, ,Rural Medical College, Pravara Institute of Medical \\ Sciences, Loni, Indial \\ ${ }^{2}$ Professor and Head of Department, Department of Pediatrics, ,Rural Medical College, Pravara Institute of \\ Medical Sciences, Loni, India \\ ${ }^{3}$ Post graduate student, Department of Pediatrics, ,Rural Medical College, Pravara Institute of Medical \\ Sciences, Loni, India \\ ${ }^{4}$ Post graduate student, Department of Pediatrics, ,Rural Medical College, Pravara Institute of Medical \\ Sciences, Loni, India \\ ${ }^{5}$ Medical officer, Muncipal Institute of Medical Science and Research, Surat, India
}

\begin{abstract}
Sturge-Weber syndrome is a rare disorder that occurs sporadically with a frequency of 1:50,000. It is characterized by facial nevus, seizures, hemiparesis, intracranial calcificationand mental retardation. We report here a case of Sturge-Weber syndrome who presentedwith features suggestive of this syndrome having facial nevus extending to other half of the forehead and upper part of eyelid. MRI showed the leptomeningealangioma with atrophy is noted ipsilateral to the leptomeningealangiomatosis and left lateral hemiatrophy with prominent sulcus spaces and extra cerebral CSF spaces. Calcifications produce a characteristic double contoured "tram-line" appearance following the convolutions of cerebral cortex. Brushfield and Wyatt stated that these tram- line calcifications are pathognomonic of SWS.
\end{abstract}

Keywords: Sturge-Weber syndrome, LeptomeningealAngiomatosis, Sporadic NeurocutaneousDisease, Brushfield and Wyatt, Nevus Flameus or Port-wine stains

\section{Introduction}

Sturge-Weber syndrome is a rare disorder that occurs with a frequency of 1: 50,000. It is a sporadic neurocutaneous diseasecharacterized by facial port-wine stain, ocular abnormalities (glaucoma andchoroidalhemangioma) and leptomeningealangioma most often involving occipital and posterior parietal lobes.(1) The syndrome consists of a constellation of symptoms and signs including a facial nevus/ capillary haemangioma, seizures, hemiparesis, intracranial calcification and mental retardation.(2)Encephalotrigeminalangiomatosis appearing as port-wine stain on face, most commonly involving the ophthalmic division of the trigeminal nerve, with maxillary and mandibular divisions less commonly involved,is characteristic.Theangiomatous lesions also involve the leptomeninges . Developmental disorders are more common when angiomas are bilateral.(3)

\section{Case Report}

A one and a half year old boy was brought to Pediatric emergency presenting withright sided tonic colonic seizures with facial twitching lasting for 45 minutes associated with frothing from mouth, loss of consciousness and right sided hemiparesis. Episode of seizures was not associated with urinary or fecal incontinence. He had similar episodes of seizures 4 months ago which wasrelieved spontaneously without any residual damage. He was born full term following uneventful birth events. He was a product of nonconsanguineous marriage and was amongst the family of two siblings who were perfectly well. Child was vaccinated and belonged to poor socioeconomic group. Patient was afebrile, normotensive, with no abnormalities in general examination except the neurocutaneous marker; port-wine stain involving upper left half of face and eyelids extending to the right half of face. Childwas drowsy but arousable with Glasgow-coma scale of 13/15. Upper motor type of right facial nerve palsy with right sided hemiparesis was seen. Ophthalmologic examination revealedno abnormality. Hematological and biochemical profile was within normal range. Skull radiograph wasnormal. MRI brain showed the leptomeningealangioma with atrophy is noted ipsilateral to the leptomeningealangiomatosis and left lateral hemiatrophy with prominent sulcus spaces and extra cerebral CSF spaces. Calcifications produce a characteristic double contoured "tram-line" appearance following the convolutions of cerebral cortex.Child responded to appropriate anticonvulsant therapy and other supportive measures.Child's residual neurological deficit resolved within 6 hours, was conscious and started taking orally. He was discharged after 3 days and advised to continue anticonvulsant therapy and regular follow-up. Features of Sturge-Webersyndrome in this child were facial port-wine stain, focal seizures opposite 
to the side of nevus, hemiparesis and MRI findings.Brushfield and Wyatt stated that these tram- line calcifications are pathognomonic of SWS.

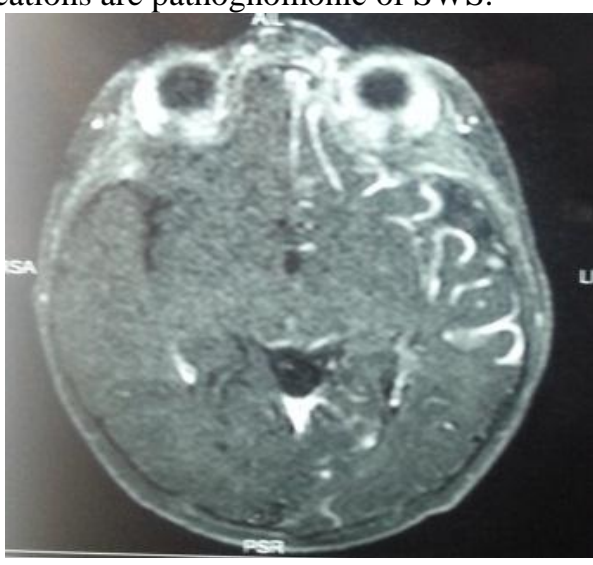

Fig 1- MRI scan showing changes of SWS

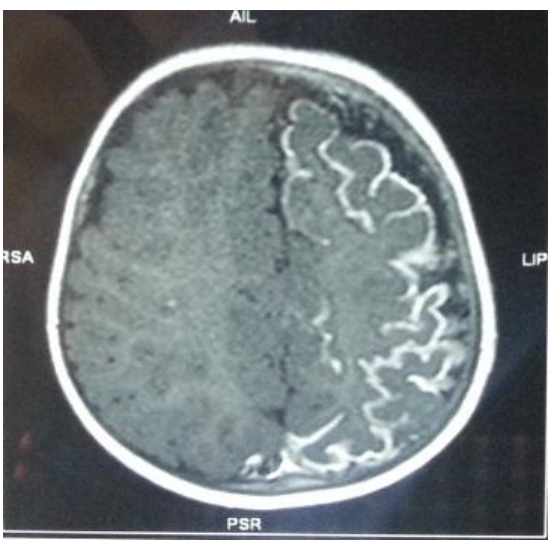

Fig 2- MRI Scan

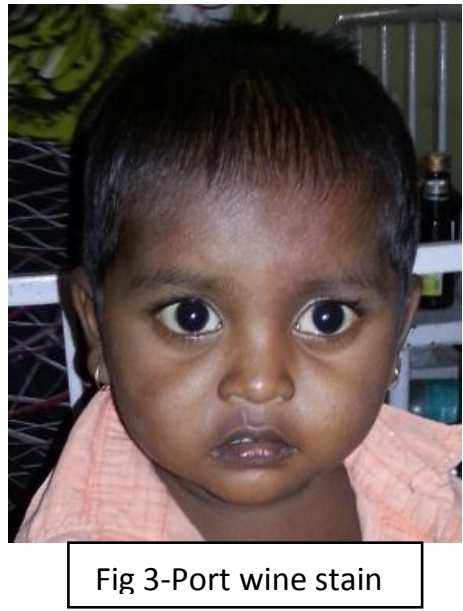

\section{Discussion}

SWS is referred to as complete when both CNS and facial angiomas are present and incomplete when only one area is affected without the other. The Roach Scale used for classification, is as follows(4):

Type I - Both facial and leptomeningealangiomas; may have glaucoma

Type II - Facial angioma alone (no CNS involvement); may have glaucoma

Type III - Isolated leptomeningealangioma; usually no glaucoma.

According to the above criteria, our case is complete Type III SWS case. Characteristically leptomeningealangiomas occur as unilateral lesions affecting the pia arachnoid membrane over the posterior temporal, parietal and occipital areas.(5) It is typically a static lesion but review of literature also reveals some progressive lesions. It commonly shows abnormal blood flow pattern as venous occlusion, thrombosis, vasomotor phenomenon and vascular steal phenomenon resulting in cortical ischemia. This in turn gives rise to epileptic convulsive crisis, transient hemiparesis, gliosis and progressive deposition of calcium salts.(6) These calcifications produce a characteristic double contoured "tram-line" appearance following the convolutions of cerebral cortex. Brushfield and Wyatt stated that these tram- line calcifications are pathognomonic of SWS.(7) These calcifications appear after the patient reaches 2 years of age and remain stationary after second decade of life. These calcifications are gyriform and curvilinear and most commonly seen in parietal and occipital lobes as seen in our case. These are seen best in the lateral skull view with affected side closer to the film.MRI shows left lateral hemiatrophy. (8)

The most evident clinical manifestation is presence of nevus flameus or Port-wine stains on the face within the distribution of Trigeminal nerve especially the ophthalmic division. They are present since birth and may range from small red macules to large red patches which blanch on pressure.(9) A large variation has been reported in their pattern of occurrence. They occur more commonly on right side and do not extend over midline. They can be bilateral or completely absent or may extend to neck, limb and other parts of body.Treatment involves early control of seizures and prevention of complications. The parents of all the 
diagnosed patientsmust receive counseling concerning thepotential risk of affected offspring. Parentsshould be educated about the potentialcomplications of the disease as well.(10)

\section{References}

[1]. Thomas-Sohl KA, Vaslow DF, MariaBL. Sturge-Weber syndrome: a review.PediatrNeurol2004; 30: 303-10.

[2]. Baselga E. Sturge-Weber syndrome.SeminCutan Med Surg2004; 23:87-98.

[3]. Haslam R. Neurocutaneous syndromes.In: Behrman RE, Kliegman RM, JensonHB, editors. Nelson Textbook ofPediatrics, 17th edn. Philadelphia: WBSaunders; 2004. p. 2015-9.

[4]. Moe P, Seay AR. Neurologic andmuscular disorders. In: Hay WW,Hayward AR, Levin MJ, SondheimerJM, editors. Current PediatricDiagnosis and Treatment, 16th edn.Singapore: McGraw Hill; 2003. p. 717-92.

[5]. Riviello JR, Baumann R, Talavera F,Mack KJ, Benbadis SR, Lorenzo N.Sturge-Weber syndrome. [online] 2005[cited 2005 Sep 27]. Availablefrom:URL:http://www.emedicine.com/n euro/topic356.htm.

[6]. Zhuo BY, Lu GJ, Ye ZZ, Han Y. A caseof Sturge-Weber syndrome.ZhonghuaErKeZqZhi2004; 42: 944.

[7]. Muniz AE. Sturge-Weber syndromepresenting as an acute life threateningevent.PediatrEmerg Care 2004; 20:610-2

[8]. Dorothy A, Kamboj M, Reddy BS,Mahajan S, Boaz K. Sturge-Webersyndrome. Indian J Dent Res.2004 Oct-Dec; 15(4):152-4.

[9]. Hussain MS, Emery DJ, Lewis JR,Johnston WS. Sturge-Weber syndromediagnosed in a 45 year old man.CMAJ2004; 170:1672.

[10]. Lisotto C, Mainardi F, Maggioni F,Zanchin G. headache in Sturge-Weber syndrome: a case report and review ofthe literature. Cephalalgia2004; 24:1001-4. 